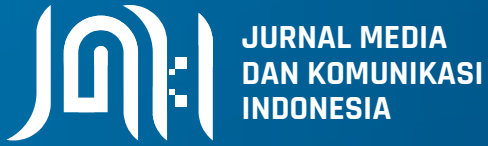

92 Strategi Penyusunan Pesan Informatif - Persuasif Dalam Data Covid-19 Oleh Humas Diskominfo Kota Bogor di Media Sosial

Shafa Tsamara Nugraini, Abdul Kholik

104 Strategi Redaksi Catch Me Up! Dalam Menghadapi Persaingan Industri Media Online

Aaron Reghanada Prasetyawibowo, Ni Made Ras Amanda Gelgel, I Gusti Agung Alit Suryawati

115 Permainan Simulasi Kencan sebagai Medium Romantic Loneliness

131 Pengaruh Kredibilitas, Kualitas Pendekatan Emosional, Dan Kualitas Isi Pesan Terhadap Efektivitas Kampanye "Love Myself" Antonia Meme 148 Informasi Kinerja Pemerintah Daerah di Media Online 


\section{Jurnal Media dan Komunikasi Indonesia}

Jurnal Media dan Komunikasi (JMKI) diterbitkan Departemen Ilmu Komunikasi, Fakultas IImu Sosial dan IImu Politik, Universitas Gadjah Mada. Terbit dua kali setahun, Maret dan September. JMKI dedikasikan untuk mempublikasikan dan mendiseminasikan penelitian, kajian, dan fenomena dalam IImu Komunikasi khususnya di Indonesia. Ruang lingkup manuskrip yang diterbitkan di JMKI adalah manifestasi dari visi Departemen Ilmu Komunikasi yaitu "Crafting Well Informed Society." JMKI mengundang para peneliti maupun praktisi dari berbagai disiplin keilmuan untuk menulis tentang kajian media dan komunikasi seperti jurnalisme dan media, media entertainment, periklanan, humas, cultural studies, film studies, dan game studies.

\section{Editor in Chief}

Rajiyem, Faculty of Social and Political Sciences Universitas Gadjah Mada

\section{Deputy Editor in Chief}

I Gusti Ngurah Putra, Faculty of Social and Political Sciences Universitas Gadjah Mada

\section{Editorial Board}

Wisnu Prasetya Utomo, Faculty of Social and Political Sciences Universitas Gadjah Mada

Widodo Agus Setianto, Faculty of Social and Political Sciences Universitas Gadjah Mada

\section{Reviewer}

Muninggar Saraswati, Swiss German University

Gregoria Arum Yudarwati, Universitas Atma Jaya

Rajab Ritonga, Faculty of Communication Science, Universitas Prof. Dr. Moestopo (Beragama)

Effendi Gazali, Universitas Prof. Dr. Moestopo (Beragama)

Megandaru Widhi Kawuryan, Departement of Government, Institut Pemerintahan Dalam Negeri (IPDN)

Hermin Indah Wahyuni, Faculty of Social and Political Sciences, Universitas Gadjah Mada

Novi Kurnia, Faculty of Social and Political Sciences, Universitas Gadjah Mada

Nunung Prajarto, Faculty of Social and Political Sciences, Universitas Gadjah Mada

\section{Editorial Secretary}

Jusuf Ariz Wahyuono, Faculty of Social and Political Sciences Universitas Gadjah Mada

\section{Mailing Address}

Departemen Ilmu Komunikasi

Jalan Sosio Yustisia No. 2 Bulaksumur

Yogyakarta 55281

Email:jmki@ugm.ac.id 


\section{Daftar ISI}

Strategi Penyusunan Pesan Informatif - Persuasif Dalam Data Covid-19 Oleh Humas Diskominfo Kota Bogor di Media Sosial

Shafa Tsamara Nugraini, Abdul Kholik

Strategi Redaksi Catch Me Up! Dalam Menghadapi Persaingan Industri Media Online

Aaron Reghanada Prasetyawibowo, Ni Made Ras Amanda Gelgel, I Gusti Agung Alit Suryawati

Permainan Simulasi Kencan sebagai Medium Romantic Loneliness

Sarah Noverianti, Ardian Indro Yuwono

Pengaruh Kredibilitas, Kualitas Pendekatan Emosional, Dan Kualitas Isi Pesan Terhadap Efektivitas Kampanye "Love Myself"

Antonia Meme

Informasi Kinerja Pemerintah Daerah di Media Online

Nur Imroatus Sholikhah 


\title{
Permainan Simulasi Kencan sebagai Medium Romantic Loneliness
}

\author{
Sarah Noverianti \\ | Mahasiswa Program Studi Sarjana IImu Komunikasi, FISIPOL, UGM. \\ Bisa dihubungi melalui email sarah.n@mail.ugm.ac.id \\ Ardian Indro Yuwono $\quad$ | Dosen Departemen IImu Komunikasi, FISIPOL, UGM. \\ Bisa dihubungi melalui email ardianindro@ugm.mail.ac.id
}

\begin{abstract}
ABSTRAK
Dating simulation game is a subgenre of simulation game, where the player-who plays as the main character surrounded by many male/female characters-interact with the game character to develop romantic relationship with one of them, through the multiple choice feature in the game. This feature will bring the gamer to a fantasy where they can meet someone who gives affection and love to them, and could date with them. Through ethnography method, this article investigate on the process and experience of playing the game to overcome their romantic loneliness by the gamers of "Mystic Messenger" (for female gamer) and "If My Heart Had Wings" (for male gamer). The results shows that the playing process is centered on the interaction's process between gamers and the game characters, through conversation dialogue and the multiple choice feature, as well as various features in the game. This process brings the gamer to be close to the character their chose, thus providing an ideal romantic relationship experience for gamers, as if they were interacting and establishing a relationship with real people.
\end{abstract}

Keywords: video game gamer, dating simulation game, romantic loneliness, Mystic Messenger, If My Heart Had Wings

\section{Pendahuluan}

Setiap orang memiliki kebutuhan akan hubungan interpersonal dan emosional dengan orang lain, dan sudah pada hakikatnya manusia dilahirkan untuk saling berinteraksi. Meskipun demikian, sebuah interaksi tidak selamanya akan membuahkan hasil yang diharapkan. Loneliness merupakan hasil atas konsekuensi tersebut, yang merupakan pengalaman subjektif atas perasaan negatif mengenai tingkat kontak sosial, dan perasaan yang kurang kuat atas hubungan intim yang dijalin (Cotten, Anderson, \& McCullough, 2013; Adamczyk, 2016). Kurangnya hubungan intim atau hubungan romantis menjadi faktor penting yang dirasakan bagi individu yang mengalami loneliness (Rokach \& Brock, 1998). Sejalan dengan emotional romantic loneliness karena terkait dengan ketiadaan pasangan atau hubungan yang dekat dan eksklusif dengan orang lain.

Seseorang yang mengalami loneliness memiliki kebutuhan akan komunikasi interpersonal, namun cenderung memiliki keraguan untuk menggunakan saluran interpersonal karena dianggap tidak efektif (Wang, Link, \& Cai, 2008). 
Oleh karena itu, digunakan media massa karena dianggap sebagai media alternatif yang efektif ketika komunikasi interpersonal gagal dijalankan (Rubin \& Perse, 1987). Di era digital, media digital telah menggeser peran media massa sebagai pilar kehidupan sosial manusia. Teknologi dan koneksi digital hadir untuk menyediakan ilusi atas hubungan kepada setiap pengguna, sehingga juga berperan sebagai jalan keluar bagi yang mengalami loneliness. Alat pemuas kebutuhan untuk menjalin hubungan, baik sosial maupun romantis, tidak selamanya berwujud nyata, melainkan maya (Turkle, 2011). Salah satunya adalah permainan simulasi kencan, di mana pemain dapat merasakan cinta dan afeksi, berinteraksi dan menjalin hubungan intim dan romantis secara virtual dengan karakter permainan.

Permainan simulasi kencan merupakan salah satu bentuk permainan digital. Dalam Calleja (2010), permainan digital erat kaitannya dengan media yang digunakan pemain untuk keluar dari realitas dan masuk ke dunia virtual. Begitu pula dengan permainan simulasi kencan, yang menjadi media bagi pemain untuk keluar dari dunia nyata karena kekosongan afeksi dan menuju ke dunia virtual untuk mengisi kekosongan tersebut.

Dalam mengonsumsi permainan simulasi kencan sebagai media, pemain mempertimbangkan pemaknaannya dengan pesan dalam permainan, interaktivitasnya saat bermain dan kedekatannya dengan karakter. Untuk memenuhi kebutuhannya, pemain akan melakukan berbagai praktik. Salah satunya adalah pemain yang memasukkan kehidupan game ke dalam dunia nyata, seperti seorang pria asal Jepang bernama Sal 9000 yang menikah secara formal dengan karakter game (Lah, 2009). Fenomena ini menunjukkan bahwa pengalaman bermain memiliki peran penting, yang mana turut menciptakan perilaku pemain game sangat beragam. Pemain menanggapi secara serius atas tindakannya dalam bermain dan menjadikan game sebagai jalan keluar atas masalah yang dihadapinya. Frekuensi pemain dalam memainkan permainan simulasi kencan sama dengan lama berinteraksi dan menjalin hubungan dengan karakter game, sehingga memunculkan rasa cinta, komitmen, dan kesetiaan dengannya. Oleh karena itu, terlepas dari segala kelebihan yang terdapat di dalamnya, permainan simulasi kencan juga membuat pemain menjadi memiliki fantasi dan preferensi yang berlebihan mengenai pasangan dan hubungan romantis di dunia nyata.

Di samping itu, seorang perempuan asal Jepang bernama Ayumi Saito mengungkapkan bahwa alasannya mulai bermain permainan simulasi kencan adalah untuk mengisi rasa kesedihan dan kekosongan afeksi setelah putus dengan pacarnya (Marsh \& Ogura, 2017). Keinginan memperoleh afeksi dan pasangan yang ideal, mendorong pemain untuk memainkan permainan simulasi kencan, sebagai sarana bagi mereka untuk mengisi kekosongan afeksinya.

Akan tetapi, permainan ini tidak hanya dimainkan bagi pemain yang lajang saja. Dalam tulisannya di laman VICE, Beusman (2018) mengaku terobsesi memainkan permainan simulasi kencan meskipun memiliki pacar di dunia nyata, dan menganggap karakter dalam permainan tersebut sebagai pacar virtualnya. Fenomena ini menjadi unik karena orang yang memiliki pacar atau hubungan 
romansa dengan pasangannya pun juga memainkan permainan ini.

Berdasarkan pemaparan di atas, peneliti tertarik untuk meneliti fenomena ini, karena proses pemain memainkan permainan tersebut untuk menghadapi dan mengatasi romantic lonelinessnya belum terungkap dalam penelitian atau kajian video game yang ada. Sampai saat ini, penelitian mengenai permainan simulasi kencan masih minim di Indonesia. Fenomena ini memang belum terlihat di Indonesia, namun permainan simulasi kencan juga populer di Indonesia. Hasil survei oleh Darmawan (2015) menunjukkan bahwa hampir separuh warga Indonesia mengenal dan memainkan permainan simulasi kencan. Berdasarkan hasil survei mandiri yang dilakukan peneliti pada 5 Maret 2020 oleh 419 responden dari seluruh Indonesia, otome game "Mystic Messenger" dan bishoujo game "If My Heart Had Wings" merupakan permainan simulasi kencan terpopuler. Kemudian, Daerah Istimewa Yogyakarta menempati posisi pertama-sebanyak $41,8 \%$-sebagai provinsi dengan jumlah pemain permainan simulasi kencan terbanyak di Indonesia. Dengan demikian, dilakukan penelitian pada pemain "Mystic Messenger" dan "If My Heart Had Wings" di Daerah Istimewa Yogyakarta dan sekitarnya.

\section{Tinjauan Pustaka}

\section{Romantic Loneliness dan Peran Media Digital}

Kebutuhan akan hubungan intim merupakan salah satu motivasi dasar manusia untuk bertahan hidup. Pada usia dewasa muda, individu menganggap bahwa makna khusus dalam hidup berasal dari ikatan yang intim dengan pasangan, yang dalam periode tertentu ingin membentuk hubungan romantis yang abadi (Adamczyk \& Segrin, 2015). Kehidupan romantis yang ideal tersebut tidak selamanya hadir dalam kehidupan seseorang, baik bagi individu yang tidak memiliki pasangan maupun yang memiliki pasangan, karena untuk menciptakan hubungan romantis yang ideal memerlukan interaksi. Proses interaksi yang dilakukan seseorang pun tidak selamanya membuahkan hasil yang diharapkan, sehingga mereka mengalami romantic loneliness. Padahal seseorang yang mengalami kondisi tersebut memiliki ketergantungan yang kuat untuk berinteraksi dengan orang lain (Hasan \& Clark, 2017). Kondisi ini tidak hanya merujuk pada seseorang yang sedang 'sendirian', namun pada seseorang yang merasa bahwa hubungan yang diinginkan tidak sesuai dengan yang diharapkan dan ketiadaan hubungan yang dengan orang lain (Rokach \& Brock, 1998; Schiau, 2016). Romantic loneliness juga melibatkan perasaan yang hampa (Drennan et al., 2008), sehingga kondisi ini tidak terbatas pada apakah seseorang terlibat dalam hubungan romantis atau tidak (Luhrs, Solomon, Lubarsky, \& Vue, 2013).

Apabila saluran komunikasi interpersonal tidak efektif untuk memenuhi

kebutuhan komunikasi interpersonalnya, seseorang yang mengalami loneliness maupun menggunakan media massa sebagai penggantinya. Oleh karena sekarang dunia telah ditunjang oleh teknologi canggih, media massa yang tradisional digeser oleh media digital, sehingga penggunaan media bisa menjadi lebih personal, sebab media tersebut juga terdapat 
dimensi tekstualitas, visualitas, dan interaktivitas (Pečiulis, 2016).

Dalam Turkle (2011), keberadaan teknologi dapat menyatukan umat manusia yang mengalami segala bentuk loneliness, karena media tersebut menyediakan sarana melakukan hubungan yang intim kepada penggunanya. Dalam konteks romantic loneliness, media digital juga mampu menghadirkan keberadaan pasangan bagi pengguna untuk menjalin hubungan romantis. Oleh karena itu, apabila seseorang merasa hilang harapan pada orang lain yang menurutnya tidak sesuai dengan gagasannya tersebut, maka mereka akan beralih pada penggunaan media digital sebagai penunjang kebutuhan romansanya.

Salah satu bentuk media digital yang merujuk pada fenomena ini adalah permainan digital (video game), yang menghadirkan bentuk interaksi pemain dengan karakter dalam permainan, karena dewasa ini banyak video game yang telah merambah pada aspek interaktivitas. Terkadang kalimat yang diutarakan oleh karakter permainan memberikan dukungan emosional atas hubungan intim, sehingga dapat mengurangi rasa romantic loneliness (Luhrs, Solomon, Lubarsky, \& Vue, 2013). Permainan digital erat kaitannya dengan media yang digunakan pemain untuk keluar dari dunia nyata dan masuk ke dunia virtual (Calleja, 2010). Begitu pula dengan kaitannya dalam hal romantic loneliness, di mana seseorang yang mengalaminya dapat menggunakan video game sebagai medium untuk keluar dari dunia nyata karena kekosongan afeksi yang dialaminya, dan menuju ke dunia virtual untuk mengisi kekosongan tersebut, sehingga mereka bisa merasakan atau berimajinasi secara bebas mengenai kehidupan romantisnya dalam permainan.

\section{Video Game dan Media Hiburan}

Esposito (2005) mengemukakan definisi video game yang ditinjau dari aspek game (permainan), play (bermain), interactivity (interaktivitas), dan narrative (naratif), yang merupakan 'permainan' yang kita 'mainkan' berkat 'peralatan audiovisual' dan yang dapat didasarkan pada sebuah 'cerita'. Video game adalah permainan, yang mana permainan merupakan kegiatan interaktif di mana pemain mengikuti peraturan dan/atau tujuan yang membatasi perilaku mereka yang berakhir pada hasil yang dapat diukur (Zimmerman dalam Esposito, 2005b).

Dinamika video game menciptakan beragam tema, tujuan dan genre permainan, yang dapat dimainkan secara kompetitif atau bekerja sama, sendirian, dengan pemain lain yang hadir secara fisik, atau dengan ribuan pemain daring lainnya, yang mana dapat dimainkan dalam segala perangkat (Granic, Lobel, \& Engels, 2014). Dengan adanya dinamika tersebut, definisi video game meluas dari perspektif 'sesuatu di mana pemain bisa menang' kepada 'storytelling yang interaktif' (Townsend, 2017).

Friedman (2008) mendefinisikan video game sebagai bagian dari media karena membutuhkan partisipasi audiens (i.e. pemain) yang aktif-tidak pasif seperti film, serial televisi, dan media lainnya-dan hal ini dapat didukung dalam konteks media, di mana video game dapat ditinjau dari konsep media kontemporer.

Salah satu teori dalam kajian media yang digunakan dalam konteks video game adalah teori kultivasi. Dalam konteks video game, penerapan 
teori kultivasi dilihat dari terpaan yang berulangulang dapat membuat pemain menciptakan persepsi dan keyakinan atas realitas dunia nyata dengan dunia permainan (Chong et al., 2012).

Keberadaan video game dalam kajian media juga tidak luput dari konseptualitas populer dari media itu sendiri, di mana media tersebut cenderung sering dikarakterisasi sebagai bentuk hiburan karena dipenuhi oleh fantasi dan/atau kaya akan narasi dan storytelling (Oliver et al., 2015). Oleh karena itu, video game menyediakan kesempatan bagi pemain untuk melakukan identifikasi dengan karakter dan kemungkinan untuk mengalami berbagai macam emosi, sehingga video game tidak hanya menghibur tetapi juga bermakna.

Terdapat kajian yang menunjukkan bahwa video game sebagai media hiburan juga berkaitan erat dengan eskapisme. Dymek dan Bergvall (dalam Calleja, 2010) mengungkapkan bahwa kegiatan bermain menjadi metode untuk melarikan diri dari realitas dengan memasuki sebuah realitas yang baru dan dihasilkan oleh komputer, sehingga permainan membenamkan pemain dengan berbagai bentuk hiburan yang menciptakan pelarian dari kenyataan. Oleh karena itu, Messerly (dalam Calleja, 2010b) mengimbuhkan bahwa eskapisme merupakan daya tarik utama, terlebih ketika kualitas permainan menjadi lebih baik dan canggih, sehingga kegiatan bermain menjadi lebih mengasyikkan; dan menjadi mudah dipahami mengapa terdapat pemain yang ingin melarikan diri dari dunia nyata yang sulit dan rumit, dan jatuh ke dalam lingkungan permainan yang jelas dan menarik, sehingga mereka ingin dan dapat hidup di sana dengan sedikit atau tanpa interaksi dengan dunia nyata yang biasa.
Peran video game sebagai media hiburan inilah yang membuat video game menjadi bermakna. Osmanovic dan Pecchioni (2015) menemukan bahwa kehadiran video game juga menghibur pemain yang mengalami loneliness, karena terdapat konten dan elemen yang imersif. Oleh karena itu, video game juga turut memenuhi kebutuhan psikologis pemain, di mana ilusi yang diciptakan dalam permainan dapat mempengaruhi psikologis pemain yang mencapai pada rasa kepuasannya selama bermain (Przybylski, Rigby, \& Ryan, 2010).

\section{Pemain Game sebagai Audiens Media}

Seiring dengan berkembangnya jaman, kajian game tidak melulu membahas mengenai efek media, tetapi juga berfokus pada perannya sebagai teks media, seperti adanya konsep naratif-tentang cerita dan storytelling yang disampaikan dalam permainan; dan ludologi-tentang aktivitas pemain dan pola bermain. Dengan demikian, permainan digital atau video game dipandang sebagai permainan yang berbasis 'interaktif' dan 'simulasi', sehingga terdapat perbedaan yang jelas antara pemain game dan audiens media tradisional-yang pasif dan non-interaktif (Gosling \& Crawford, 2011). Perlu diketahui pula bahwa video game menawarkan pemainnya beberapa pilihan yang secara langsung berdampak pada hasil akhir permainan maupun hasil pengalaman setelah bermain (Newbury, 2017).

Sebagai media interaktif, video game membutuhkan partisipasi aktif dari pemain agar dapat menerima pesan. Berbeda dengan media konvensional maupun tradisional, di mana feedback audiens terhadap teks berlangsung 
secara bertahap atau bahkan tidak terjadi, sedangkan respon antara pemain dan video game yang dimainkannya terjadi secara langsung, sehingga pemain game memiliki sifat yang paralel dengan audiens aktif secara umum, yang mana menitikberatkan fokusnya terhadap elemen tertentu dari suatu teks media (Jiwandono, 2015). Bentuk partisipasi tersebut akan mengarah pada pengalaman bermain yang kuat. Pengalaman ini dapat mempertahankan tindakan dan atensi pemain, karena pemain menentukan tindakan karakter yang dimainkannya dan menentukan bagaimana jalannya cerita hingga akhir permainan. Pengalaman ini juga mengacu pada gameplay dalam permainan. Dimensi dalam gameplay menyediakan pengalaman yang imajinatif atas dunia fiksi, dan pendekatan ini telah menjadi salah satu sifat video game (Biggin, 2017). Oleh karena itu, dengan pengalaman tersebut, pemain merasa masuk ke dalam cerita dalam permainan, yang disebut sebagai pengalaman immersive, dimana pemain seolah-olah masuk ke dalam dunia permainan (Sánchez et al., 2012), dan mengarah pada peredaman psikologis, yakni mempengaruhi emosi atau sisi psikis pemain (Newbury, 2017).

Burn (dalam Gosling \& Crawford, 2011) menuliskan bahwa pengalaman pemain game tidak berhenti ketika sesi permainan selesai dan perangkat dimatikan, tetapi melanjutkannya dengan berpikir, berimajinasi, dan bahkan bermimpi tentang cerita, lanskap, dan karakter dalam permainan. Selain itu, pemain akan menjadi penggemar permainan tersebut, sehingga berkomitmen untuk melangkah lebih jauh dengan komunitas penggemar permainan tersebut (baik komunitas daring maupun fisik), berkontribusi pada papan pesan dalam forum permainan, membuat fanart, menulis fanfiction dan/atau walkthrough, membeli dan menggunakan merchandise atau benda yang berhubungan dengan permainan tersebut, dan lain sebagainya.

4. Permainan Simulasi Kencan sebagai Medium Romantic Loneliness

Permainan simulasi kencan adalah bagian dari video game genre simulasi, yang secara singkat didefinisikan sebagai permainan di mana pemain melakukan simulasi berpacaran dengan karakter dalam permainan. Taylor (2007) menyebutkan bahwa permainan ini berfokus pada kencan atau romansa dan kemungkinan mengandung konten erotis. Tujuan permainan ini dimainkan juga untuk terlibat dalam suatu hubungan dengan salah satu karakter sebelum permainan berakhir (Zoggel, 2011).

Selain sebagai pengisi waktu, permainan simulasi kencan juga menjadi pengisi kekosongan romansa pemain di dunia nyata. Taylor (2007), yang menyatakan bahwa permainan ini digunakan sebagai jalan keluar untuk dapat berekspresi secara bebas dimana pemain dapat melarikan diri dari realitas dan norma-norma sosial, sehingga mereka masuk ke dalam imajinasi atas kehidupan atau hubungan romantisnya. Mei Erikawa, selaku Direktur dan Kepala "Ruby Party" (sebuah pengembang otome game), yang mengungkapkan bahwa otome game-yang mewakili permainan simulasi kencan pada umumnya-diciptakan untuk mewadahi pemain untuk membuat 'cerita'nya sendiri agar dapat terhibur dan mengisi kekosongan afeksi karena setiap orang tidak akan 
pernah berhenti membutuhkan rasa cinta (Lee, 2018).

Pemain yang menggemari dan/atau yang berdedikasi pada permainan bergenre romantis maupun permainan simulasi kencan sebagian besar tidak menganggap bahwa interaksi mereka dengan karakter dalam permainan sebagai pengganti persahabatan manusia, tetapi sebagai tipe baru menjalin keintiman secara digital. Oleh karena itu, permainan simulasi kencan dipandang sebagai 'pelarian', yakni pilihan alternatif dan terakhir bagi seseorang yang membutuhkan gadis atau pria virtual untuk menggantikan hubungan yang nyata dan sehat. Seorang komentator asal Tiongkok berpendapat bahwa satu-satunya alasan pemain tertarik untuk memainkan permainan tersebut adalah karena mereka kurang merasakan dan memperoleh cinta sejati di kehidupan nyata (Schwartz, 2018).

Permainan simulasi kencan, yang berperan sebagai media romantis, sering mengambarkan cinta sebagai sesuatu yang kuat, tak tergoyahkan, dan mampu mengatasi semua hambatan atau cobaan dalam hidup. Hal ini tentu dapat meningkatkan kadar romantic loneliness seseorang karena memberikan ilusi dan ekspektasi yang tidak realistis, tetapi di sisi lain juga membuat mereka semakin membutuhkan media tersebut untuk mengatasi romantic loneliness-nya.

\section{Metode}

Penelitian ini menggunakan pendekatan kualitatif dan metode etnografi karena meninjau proses bermain yang dilakukan pemain permainan simulasi kencan, sehingga dapat menjelaskan cara dan pengalaman bermain dan proses pemain memaknai pesan dalam permainan sebagai sarana memenuhi kebutuhannya akan pengisi kekosongan afeksi, yang mana berdampak pada sisi emosi dan kehidupan sosialnya.

Dengan metode yang mengadopsi langkah penelitian etnografi Spradley (dalam Ary, Jacobs, Sorensen, \& Razavieh, 2010 dan Creswell, 2012), proses penelitian diawali dengan menetapkan informan, melakukan wawancara terhadap informan, dan dilanjutkan dengan mengajukan pertanyaan etnografis. Setelah melakukan wawancara, peneliti mengumpulkan data etnografi, yakni melakukan pengamatan deskriptif dan terfokus, seperti observasi partisipan, wawancara mendalam, dan dokumen. Semua data yang terkumpul dianalisis secara etnografis, yakni menyelidiki dan menemukan berbagai temuan yang diperoleh dari informan, namun tetap mengaitkannya dengan permasalahan yang asli, meskipun mengarah pada pertanyaanpertanyaan dan hipotesis baru. Penelitian diakhiri dengan menulis etnografi atau hasil penelitian, yang dilakukan secara deskriptif.

Dalam kajian komunikasi, metode etnografi menyediakan serangkaian konsep untuk memahami dan menganalisis praktik komunikasi sebagai perwujudan dari kehidupan sosial, sehingga melibatkan berbagai prosedur analisis yang termasuk pengamatan subjek penelitian dalam konteks kehidupan sehari-hari, sosial, dan wawancara (Carbaugh \& Habashi, 2015).

Dalam penelitian ini, untuk mengidentifikasi proses pemain menggunakan permainan simulasi kencan sebagai medium romantic loneliness, 
peneliti mengadopsi playability model oleh Sánchez et al. (2012) untuk mengetahui pengalaman pemain dalam memainkan permainan simulasi kencan untuk mengatasi romantic lonelinessnya.

Subjek yang diteliti adalah tiga informan yang dipilih berdasarkan teknik purposive, di mana pengumpulan informan didasarkan pada pertimbangan dan tujuan tertentu. Hasil elaborasi kriteria informan dan hasil survei peneliti mengenai pemain permainan simulasi kencan di Indonesia menghasilkan spesifikasi ketiga informan, yakni sebagai berikut:
Mengidentifikasi Pengalaman Bermain Tahap I

melalui Playability Model (Sánchez et al., 2012)

\begin{tabular}{|c|c|c|c|c|}
\hline $\begin{array}{l}\text { Effectiveness } \\
\text { - Structuring } \\
\text { - Completion }\end{array}$ & $\begin{array}{l}\text { Learnability } \\
\text { - Game } \\
\text { Knowledge } \\
\text { - Skill } \\
\text { - Speed } \\
\text { - Difficulty } \\
\text { - Frustration } \\
\text { - Discovery }\end{array}$ & $\begin{array}{l}\text { Immersion } \\
\text { - Conscious } \\
\text { Awareness } \\
\text { - Realism }\end{array}$ & $\begin{aligned} & \text { Satisfaction } \\
& \text { - Fun } \text { - Disappointment } \\
& \text { - Attractiveness }\end{aligned}$ & $\begin{aligned} & \text { Motivation } \\
& \text { - Encouragement } \\
& \text { - Curiosity } \\
& \text { - Self-Improvement } \\
& \text { - Diversity }\end{aligned}$ \\
\hline
\end{tabular}

Tipe Pemain Permainan Simulasi Kencan (Tanikawa \& Asahi, 2013)

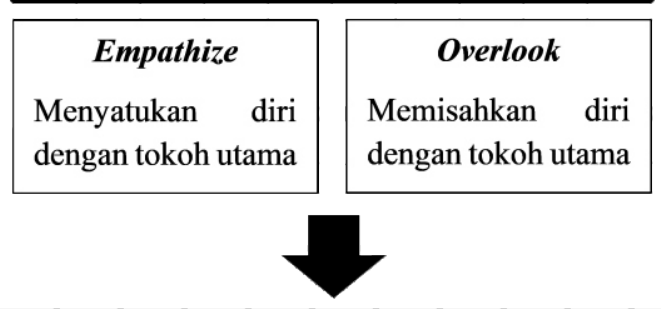

Mengidentifikasi Pengalaman Bermain Tahap II melalui Playability Model (Sánchez et al., 2012)

\begin{tabular}{|l|l|}
\hline \multicolumn{1}{|c|}{ Emotion } \\
- Reaction \\
- Conduct \\
- Sensory Appeal
\end{tabular} \mid \begin{tabular}{c}
\multicolumn{1}{c|}{ Socialization } \\
- Social Perception \\
- Personal Implication \\
- Interaction
\end{tabular}

Tabel 1 Tabel Kerangka Konsep Penelitian 


\begin{tabular}{|l|l|l|}
\hline \multicolumn{1}{|c|}{ Informan I } & \multicolumn{1}{|c|}{ Informan II } & \\
\cline { 2 - 3 } - Laki-laki & - Perempuan & - Perempuan \\
- Pemain Aktif & - Pemain Aktif & - Pemain Aktif \\
- Lajang & - Hubungan Tanpa Status & - Memiliki Pacar \\
- Mahasiswa (Usia Dewasa Muda) & - Mahasiswa (Usia Dewasa Muda) & - Mahasiswa (Usia Dewasa Muda) \\
- Mengalami Romantic Loneliness & - Mengalami Romantic Loneliness & - Mengalami Romantic Loneliness \\
\hline
\end{tabular}

Tabel 2 Tabel Klasifikasi Subjek Penelitian

\section{Hasil dan Pembahasan}

Proses pemain game melakukan kegiatan bermain permainan simulas kencan dari tahap memulai permainan hingga hasil akhir dari kegiatan bermai tersebut merupakan tahap pembentukan pengalaman bermain, yang mana akan diketahui bagaimana pemain menggunakan permainan tersebut sebagai wadah untuk mencapai suatu tujuan-karena pada dasarnya suatu tindakan selalu dilandasi pada alasan tertentu. Terdapat berbagai faktor yang melandasi pemain untuk melakukan kegiatan bermain tersebut. Dalam konteks permainan simulasi kencan (yang menjadi subjek utama dalam penelitian ini), faktor utama yang melandasi kegiatan tersebut adalah mengatasi atau mengurangi romantic loneliness yang dialaminya, selain sebagai media hiburan.

Sebelumnya akan dibahas mengenai tujuan informan-yang merupakan pemain game-memainkan permainan simulasi kencan. Informan Morgan pada awalnya memainkan permainan tersebut karena rasa penasaran, namun lambat laun beralih pada keinginan untuk mendapat hiburan melalui cerita di dalamnya, dan menjalin hubungan dengan karakter yang cantik. Keinginannya untuk berkencan dengan perempuan melalui permainan tersebut juga didorong oleh pengalaman cintanya yang buruk di masa lalu, yang mana membuatnya berstatus lajang sejak saat itu, padahal ingin memiliki pacar atau mengalami perasaan romantis dengan siapapun. Hal ini membuatnya mengalami romantic loneliness karena tidak memiliki seseorang untuk berbagi perasaan dan melakukan hal yang disukainya bersama-sama.

Informan Ganmo mulai memainkan permainan simulasi kencan karena merasa bosan dan penasaran dengan permainan tersebut, yang mana setelah mencoba memainkan satu judul permainan, dia menjadi ingin memainkan judul yang lain karena dia menemukan begitu banyak karakter pria tampan di dalamnya. Di samping itu, sebenarnya Ganmo juga memainkannya untuk mengatasi rasa kesepiannya, di mana dia ingin memiliki pria yang berada di sampingnya layaknya serial drama romansa dan merasa iri ketika melihat teman di kampusnya yang telah memiliki pasangan. Pada akhirnya dia berhasil menjalin hubungan romantis dengan seseorang, meskipun tidak berstatus pacaran, melainkan hubungan tanpa status. Namun, hal tersebut tidak dapat menyembuhkan romantic loneliness-nya, yang justru membuatnya merasa menyesal dan 
canggung. Oleh karena itu, Ganmo tetap memainkan permainan tersebut, karena dia bisa menjalin hubungan tanpa rasa canggung.

"Ku kira dengan punya hubungan romantis sama orang gitu bisa ngilangin romantic loneliness-ku itu, tapi malah makin parah ... Untungnya aku masih punya otoge, ... aku bisa gak ngerasa canggung berinteraksi sama cowok ... aku ngerasa nyaman bisa berhubungan sama orang ... dan aku gak ada ngerasa kepikiran macem-macem." (Ganmo, personal communication, April 24, 2020) Tujuan utama informan Reza memainkan permainan tersebut adalah memang untuk mengatasi romantic loneliness-nya, karena merasa kesepian menjalani hubungan jarak jauh dengan pacarnya. Tidak menutup kemungkinan bahwa seseorang yang memiliki hubungan yang terikat dengan orang lain pun juga mengalami kesepian, khususnya romantic loneliness. Oleh karena itu, Reza mengalihkan rasa kesepian dan pikiran-pikiran tersebut melalui permainan simulasi kencan.

Mengetahui tujuan informan memainkan permainan tersebut, yakni untuk mengatasi atau mengurangi romantic loneliness-nya, peneliti mengidentifikasi bagaimana mereka menggunakan permainan tersebut untuk mencapai tujuannya, yakni dengan melalui proses dan pengalaman bermainnya. Berdasarkan hasil temuan yang diperoleh di lapangan, kegiatan bermain tersebut menghasilkan suatu pengalaman berhubungan romantis dengan love interest, yakni melalui bentuk percakapan antara dirinya (sebagai karakter tokoh utama) dengan love interest-nya, di mana mereka berinteraksi dengannya melalui pilihan jawaban yang disediakan dalam permainan, dan melalui berbagai fitur yang di dalamnya; dan cerita yang disajikan dalam permainan. Ketika berinteraksi dengan love interest dan memahami cerita dalam permainan, mereka mengambil pesan tersirat yang ada di dalamnya dan membayangkan dirinya berada di dalam posisi yang sama dengan karakter tokoh utama. Unsur interaktivitas dalam permainan tersebut membuat pemain bisa terlibat di dalamnya, yang mana pemain juga berperan untuk menentukan hasil akhir permainan (atau ending), selain berinteraksi dengan karakter maupun love interest layaknya berinteraksi dengan orang sungguhan. Berdasarkan pengalaman bermain Ganmo dan Reza, mereka melibatkan sisi emosionalnya ketika bermain, sehingga dapat mendalami cerita dan karakter permainan, serta bersimpati dan berempati dengan love interest.

Menurut Morgan, permainan simulasi kencan adalah media yang bisa memberikan pengalaman berkencan bagi pemain. Permainan tersebut juga bisa membantu orang yang merasa bingung untuk belajar dari skenario yang telah ada. Selain itu, sejalan dengan Sánchez et al. (2012) bahwa permainan tersebut juga memberikan pengalaman yang immersive, di mana pemain bisa merasa seolah-olah masuk dan hanyut dalam alur cerita, sehingga telah memberikan pengalaman yang sangat menarik.

Hanya melalui permainan tersebut Morgan dapat merasakan suka dan duka memiliki pasangan, memiliki kehidupan yang berwarna, dan menjadi orang yang dibutuhkan oleh orang lain. Permainan tersebut juga telah mengajarkannya mengenai cara membuat keputusan yang tepat, belajar 
menjadi orang baik, dan menambah wawasan.

"Dari main sim juga aku bisa berkaca sama keputusan yang aku buat ... Dari sim itu juga kan aku bisa belajar lebih tentang cewek, tentang temen, tentang diri sendiri, jadi bisa jadi bekal juga buat nyari hubungan beneran." Morgan, personal communication, April 25, 2020)

Melalui permainan tersebut, Morgan juga dapat mengatasi rasa romantic loneliness-nya-di mana sampai saat ini masih berstatus lajang, dan masih merasa kesulitan untuk memulai pendekatan maupun hubungan romantis dengan seseorang. Kemudian, menurut Ganmo, otome gamepermainan simulasi kencan yang ditargetkan pada pemain perempuan-merupakan media yang menyajikan ilusi berpacaran atau menjalin hubungan romantis dengan pria tampan dengan akhir yang bahagia. Permainan ini juga memberikan pengalaman mengenai pendekatan dengan pria tampan, pengalaman berkencan dengannya, dan mengajarkan banyak hal, seperti cara membuat keputusan yang tepat bagi kedua belah pihak, memahami perasaan orang lain dari berbagai sudut pandang melalui adanya pilihan jawaban yang tersedia dan keberadaan love meter, dan berempati maupun bersimpati kepadanya. Sesuai dengan namanya, yakni simulasi kencan, permainan tersebut memberikan pandangan dan gambaran kepada pemain mengenai kencan, seperti suka duka berpacaran dan apa saja yang dihadapi seseorang ketika berpacaran. Oleh karena itu, permainan ini menjadi tepat sebagai wadah untuk melakukan eskapisme-yang lelah dengan kenyataan dan merasa mustahil berkencan dengan pria tampan di dunia nyata.
Di samping itu, permainan simulasi kencan juga menjadi media yang nyaman bagi Ganmo untuk menjalin hubungan romantis dengan seseorang, yang mana dia tidak akan merasa patah hati. Pengalaman teman dan kerabatnya yang mengalami hubungan yang kandas dan patah hati membuatnya merasa takut untuk memiliki pacar. Kehadiran permainan tersebut menjadi jalan keluar bagi Ganmo yang ingin menjalin hubungan romantis namun takut melakukannya di dunia nyata karena merasa ragu, sebab permainan tersebut menyajikan fantasi hubungan romantis yang nyaman dan bahagia dengan karakter (atau love interest) idaman yang ideal.

Tidak semua romantic loneliness yang dialami seseorang bisa diatasi dengan menjalin hubungan romantis. Begitu pula dengan yang dialami oleh Ganmo, di mana hubungan tanpa status yang dijalinnya tidak dapat menyembuhkan romantic loneliness, yang justru membuatnya merasa menyesal dan canggung. Hanya dalam permainan tersebut Ganmo tidak memikirkan banyak hal, merasa cemas dan khawatir ketika berhubungan romantis.

"... Cuma di otoge aku gak bisa ngerasa patah hati pas berhubungan sama orang yang aku suka." (Ganmo, personal communication, April 24, 2020) Hal yang dialami Ganmo selama memainkan permainan simulasi kencan merupakan hasil dari permainan yang diperpanjang olehnya dalam dunia permainan, yang mana dia telah mengembangkan hubungan yang mendalam dengan karakter tokoh utama (i.e. mengidentifikasikan dirinya sebagai karakter tokoh utama) maupun love interest. Hal ini membuktikan pendapat Song dan Fox (2015) 
bahwa apabila hal ini terus dilakukan, maka akan mengarah pada perubahan keyakinan, sikap dan perilaku sesuai dengan pengalaman karakter tersebut. Hal ini dapat dilihat dengan munculnya perasaan nyaman dan fantasi atas hubungan romantis yang ideal, yang mana belum pernah dirasakannya sebelum memainkannya.

Begitu pula dengan pendapat Reza, di mana permainan simulasi kencan telah membuatnya merasa bahagia. Melalui permainan tersebut, dia tidak lagi merasa romantic loneliness dari hubungan jarak jauh dengan pacarnya, dan dia bisa menjadi dirinya sendiri tanpa memikirkan faktor-faktor lainnya. Di samping itu, hanya melalui permainan tersebut, Reza bisa menemukan cara yang menghibur dan menyenangkan untuk mengatasi romantic loneliness-nya. Meskipun hanya dalam bentuk percakapan-dalam hal ini instant messanging-dan tidak nyata, pemain bisa merasakan kesenangan tersebut. Oleh karena itu, permainan tersebut telah berhasil membuat pemain bisa berkencan dengan pria tampan dan ideal tanpa memikirkan nyata atau tidaknya pengalaman kencan tersebut.

"Bahagia banget pas main game ini! Aku jadi merasa enggak kesepian, dan aku bisa jadi diriku sepenuhnya ... Gara-gara game ini aku juga jadi sadar bahwa merasakan romantic loneliness adalah hal yang wajar, tapi untungnya aku menemukan cara yang menyenangkan buat mengatasinya, yaitu melalui game ini." (Reza, personal communication, April 27, 2020)

Dengan demikian, bentuk pengalaman bermain tersebut yang menjadikan permainan simulasi kencan berperan sebagai medium mengatasi romantic loneliness bagi mereka. Di samping itu, hal ini juga mendukung argumen Schwartz (2018) bahwa pemain permainan simulasi kencan tidak menganggap interaksi mereka dengan love interest sebagai pengganti persahabatan antar manusia, tetapi lebih kepada tipe baru dalam menjalin keintiman secara digital.

\section{Kesimpulan}

Romantic loneliness sudah menjadi kondisi yang lumrah terjadi pada seseorang di seluruh dunia. Meskipun hasil penelitian terdahulu mengungkapkan bahwa usia dewasa muda yang mendominasi usia orang yang mengalaminya, tidak menutup kemungkinan bahwa seseorang dengan bukan dari kelompok usia tersebut juga mengalaminya. Kondisi romantic loneliness juga tidak memandang gender dan jenis kelamin seseorang. Pada dasarnya

kondisi tersebut sudah menjadi wajar lahir di dalam diri manusia, terutama pada sisi psikologisnya. Oleh karena itu, kondisi tersebut juga tidak melihat apakah seseorang tersebut sedang dalam hubungan maupun tidak, meskipun upaya mengatasinya adalah menjalin hubungan, sebagaimana yang ditemukan dalam penelitian ini bahwa yang menjalin hubungan romantis yang terikat pun kerap

mengalami kondisi tersebut. Kemudian, untuk bisa menjalin hubungan, seseorang yang mengalaminya perlu berinteraksi dengan orang lain hingga bisa menjalin hubungan. Namun, hal tersebut tidak mudah dilakukan, terutama apabila seseorang tersebut tidak pandai berkomunikasi dan/atau merasa putus asa ketika menggunakan 
saluran komunikasi interpersonal (atau tatap muka). Dengan demikian, media digital hadir untuk menggantikan saluran tersebut. Salah satunya adalah kehadiran video game bergenre simulasi kencan, di mana seseorang yang memainkannya (dalam hal ini, pemain) bisa berinteraksi dengan karakter (atau love interest) dalam permainan hingga bisa menjalin hubungan romantis dengan salah satu karakternya. Sebagai salah satu produk media hiburan, permainan tersebut menyajikan konten yang menghibur pemain, dan menyediakan ilusi atau fantasi kepada pemain mengenai kehidupan romansa yang ideal dan menyenangkan, sehingga bisa menjadi jalan keluar bagi pemain yang melakukan eskapisme.

Dalam permainan tersebut, pemain juga berperan sebagai audiens aktif karena ikut terlibat di dalamnya, seperti memilih jawaban dari pilihan jawaban yang tersedia. Dengan kata lain, tindakan pemain dalam permainan dapat mendukung jalannya cerita hingga akhir permainan.

Setiap pemain membutuhkan proses ketika bermain agar bisa menyesuaikan tujuan utamanya bermain dengan tujuan dalam permainan, sehingga pada akhirnya dapat mencapai hasil akhir yang memuaskan. Proses pertama adalah beradaptasi dengan sistem, mekanisme maupun gameplay dalam permainan, yakni dengan mempelajari berbagai fitur di dalamnya dan mengetahui tujuan dan tantangan yang disediakan. Membutuhkan waktu yang singkat dalam proses adaptasi bagi pemain yang sudah terbiasa dengan gameplay genre permainan tersebut, seperti Morgan dan Ganmo, karena telah memiliki pengetahuan dasar mengenai permainan tersebut. Tujuan utamanya bermain adalah untuk mengatasi romantic loneliness-nya, namun terdapat tujuan lainnya ketika menghadapi tantangan dalam permainan, yakni mencapai ending yang bagus dengan karakter atau love interest favoritnya. Hal ini mempengaruhi pemain terhadap proses menentukan pilihan jawaban dalam permainan.

Proses kedua adalah interaksi antara pemain dengan permainan. Masing-masing memiliki cara interaksi tersendiri ketika bermain, yang menurutnya nyaman, efektif, dan bisa membuatnya fokus. Terdapat berbagai upaya yang dilakukan pemain ketika bermain, seperti ada yang menggunakan intuisinya, menggunakan walkthrough demi memperoleh ending yang bagus, dan melalui proses mempelajari sifat para karakter. Unsur storytelling dan perkembangan karakter membuat pemain bisa hanyut dalam permainan dan turut bersimpati dengan para karakter. Selain itu, pemain juga memaknai isi pesan di dalamnya, sehingga mengetahui premis cerita permainan. Hal ini juga mempengaruhi bagaimana pemain bertindak dalam permainan, seperti ketika menentukan pilihan jawaban.

Proses terakhir adalah hasil akhir yang diperoleh pemain. Permainan tidak hanya berhenti pada ending yang diperoleh, tetapi juga dapat dilanjutkan dengan berbagai kegiatan, seperti membuka fitur sekuel dan spin-off dalam permainan, di mana pemain dapat merasakan momen yang berkelanjutan dengan karakter favoritnya. Selain itu, hasil akhir setelah menamatkan permainan tersebut dapat dilihat dari aspek emosi atau perasaan pemain, yakni didominasi oleh perasaan senang. Meskipun 
hanya dalam bentuk percakapan dan tidak nyata, pemain bisa merasakan kesenangan tersebut. Aspek sosialisasi tidak begitu mempengaruhi pemain secara praktis, namun lebih kepada mendorong mereka untuk mencoba mengubah kontak sosial yang menjadi lebih baik.

Dengan demikian, proses memainkan permainan simulasi kencan berpusat pada proses interaksi antara pemain dengan karakter dalam permainan, yakni melalui dialog percakapan dan fitur pilihan jawaban, serta berbagai fitur yang ada di dalamnya. Hal ini menunjukkan bahwa fitur-fitur dalam permainan itulah yang mendukung pendekatan antara pemain dengan karakter. Proses ini yang mendekatkan pemain dengan karakter yang menjadi pasangannya, sehingga memberikan pengalaman hubungan romantis yang ideal bagi pemain-seakan-akan sedang berinteraksi dan menjalin hubungan dengan orang sungguhan.

\section{Daftar Pustaka}

Adamczyk, K. (2016). An investigation of loneliness and perceived social support among single and partnered young adults. Current Psychology, 35(4), 674-689. doi: 10.1007/s12144-015-9337-7

Adamczyk, K. \& Segrin, C. (2015). Direct and indirect effects of young adults' relationship status on life satisfaction through loneliness and perceived social support. Psychologica Belgica, 55(4), 196211. doi: $10.5334 / p b . b n$

Ary, D., Jacobs, L. C., Sorensen, C., \& Razavieh, A. (2010). Introduction to research in education (8th ed.). Belmont, CA: Wadsworth CENGAGE Learning.

Biggin, R. (2017). Immersive theatre and audience experience: Space, game and story in the work of Punchdrunk. Cham, Switzerland: Palgrave Macmillan.

Beusman, C. (2018, December 30). My sensual journey into Japan's $\$ 90$ million fake anime boyfriend market. Retrieved from https://www.vice.com/en_au/article/qkg 74b/my-sensual-journey-into-japans-90million-fake-anime-boyfriend-market

Calleja, G. (2010). Digital games and escapism. Games and Culture, 5(4), 335-353. doi: $10.1177 / 1555412009360412$

Carbaugh, D. \& Habashi, D. (2015). Ethnography of communication. The International Encyclopedia of Language and Social Interaction, 1-16. doi: 10.1002/ 9781118611463.wbielsi119

Chong, Y. M. G., Teng, K. Z. S., Siew, S. C. A, \& Skoric, M. M. (2012). Cultivation effects of video games: A longer-term experimental test of first- and second-order effects. Journal of Social and Clinical Psychology, 31(9), 952971. doi: 10.1521/jscp.2012.31.9.952

Cotten, S. R., Anderson, W. A., \& McCullough, B. M. (2013). Impact of internet use on loneliness and contact with others among older adults: Cross-sectional analysis. Journal of Medical Internet Research, 15(2), e39. doi: 10.2196/jmir.2306

Creswell, J. W. (2012). Educational research: Planning, conducting and evaluating quantitative and qualitative research (4th ed.). Boston, MA: Pearson Education, Inc. 
Darmawan, D. R. (2015). Dating simulator in Indonesia. Sisforma, 2(1), 1-4. doi: 10.24167/sisforma.v2i1.402

Drennan, J., Treacy, M., Butler, M., Byrne, A., Fealy, G., Frazer, K., \& Irving, K. (2008). The experience of social and emotional loneliness among older people in Ireland. Ageing and Society, 28(8), 1113-1132. doi: $10.1017 /$ S0144686X08007526

Esposito, N. (2005). A short and simple definition of what videogame is. Proceedings of BiGRA 2005 Conference: Changing Views Worlds in Play. Retrieved from http://summit.sfu.ca/collection/

Friedman, T. (2008, December 1). The play paradigm: What media studies can learn from game studies. Retrieved from https://www.flowjournal.org/2008/12/th e-play-paradigm-what-media-studiescan-learn-from-game-studies-tedfriedman-georgia-state-university/

Gosling, V. K. \& Crawford, G. (2011). Game scenes: Theorizing digital game audiences. Games and Culture, 6(2), 135-154. doi: $10.1177 / 1555412010364979$

Granic, I., Lobel, A., \& Engels, C. M. E. (2014). The benefits of playing video games. American Psychologist, 69(1), 66-78. doi: $10.1037 / a 0034857$

Hasan, M. \& Clark, E. M. (2017). I get so lonely, baby: The effects of loneliness and social isolation on romantic dependency. The Journal of Social Psychology, 157(4), 429444. doi: $10.1080 / 00224545.2016 .12$ 29251

Jiwandono, H. P. (2015). Analisis persepsi pemain terhadap serial video game Grand Theft Auto. Jurnal Studi Pemuda, 4(1), 206-223. doi: 10.22146/studipemudaugm. 36730

Lah, K. (2009, December 17). Tokyo man marries video game character. Retrieved from http://edition.cnn.com/2009/WORLD/asi apcf/12/16/japan.virtual.wedding/

Lee, A. (2018, September 20). How the creators of the otome genre bring romance to modern audiences. Retrieved from https://www.vice.com/en_us/article/ev7 z4m/otome-genre-vita-dating-sim

Lurs, C., Solomon, A., Lubarsky, M., \& Vue, N. (2013). Loneliness and social networks. Retrieved from http://wp.stolaf.edu/ sociology/files/2013/06/Loneliness-andSocial-Networks.pdf

Marsh, J. \& Ogura, J. (2017, November 2). The rise of romance gaming: Is the perfect boyfriend inside your phone? Retrieved from https://edition.cnn.com/2016/ 11/21/asia/romance-gaming-japan/

Newbury, E. (2017, March 28). Understanding gaming audiences. Retrieved from https://www.wilsoncenter.org/blogpost/understanding-gaming-audiences

Oliver, M. B., Bowman, N. D., Woolley, J. K., Rogers, R., Sherrick, B. I., \& chung, M-y. (2015). Video games as meaningful entertainment experiences. Psychology of Popular Media Culture, 390-405. doi: 0.1037/ppm0000066

Osmanovic, S. \& Pecchioni, L. (2015). Beyond entertainment: Motivations and outcomes of video game playing by older adults and their younger family members. 
Games and Culture, 11(1-2), 130-149. doi: $10.1177 / 1555412015602819$

Pečiulis, Z. (2016). Digital era: From mass media towards a mass of media. Filosofija Sociologija, 27(3), 238-246. Retrieved from https://www.researchgate.net/ publication/308053038

Przybylski, A. K., Rigby, C. S., \& Ryan, R. M. (2010). A motivational model of video game engagement. Review of General Psychology, 14(2), 154-166. doi: 10.1037/a0019440

Rokach, A. \& Brock, H. (1998). Coping with loneliness. The Journal of Psychology: Interdisciplinary and Applied, 132(1), 107128. doi: 10.1080/00223989809599269

Rubin, A. M. \& Perse, E. M. (1987). Audience activity and soap opera involvement: $A$ uses and effects investigation. Human Communication Research, 14(2), 246-268. doi: 10.1111/j.1468-2958.1987.tb0012 9.x

Sánchez, J. L. G., Vela, F. L. G., Simarro, F. M., \& Padilla-Zea, N. (2012). Playability: Analysing user experience in video games. Behavior \& Information Technology, 1-22. doi: 10.1080/0144929X.2012.710648

Schiau, I. (2016). Humor, loneliness and interpersonal communication: A quantitative study of Romanian older adults. Journal of Communication and Public Relations, 18(1), 89-106. doi: 10.21018/rjcpr.2016.1.204

Schwartz, O. (2018, September 26). Love in the time of Al: Meet the people falling for scripted robots. Retrieved from https://www.theguardian.com/technolo gy/2018/sep/26/mystic-messengerdating-simulations-sims-digital-intimacy

Song, W. \& Fox, J. (2016). Playing for love in a romantic video game: Avatar identification, parasocial relationships, and Chinese women's romantic beliefs. Mass Communication and Society, 19(2), 197-215. doi: 10.1080/15205436.2015. 1077972

Taylor, E. (2007). Dating-simulation games: Leisure and gaming of Japanese youth culture. Southeast Review of Asian Studies, 29, $192-208$. Re trieved from https://pdfs.semanticscholar.org/f789/0 57922bcbf331d205e6b68647e9b5fe1a4 2c.pdf

Townsend, J. (2017, March 6). Gaming and the future of entertainment media. Retrieved from http://itsecurity.co.uk/2017/03 /gaming-future-entertainment-media/

Turkle, S. (2011). Alone together: Why we expect more from technology and less from each other. New York: Basic Books.

Wang, Q., Fink, E. L., \& Cai, D. A. (2008). Loneliness, gender, and parasocial interaction: A uses and gratifications approach. Communication Quarterly, 56(1), 87-109. doi: 10.1080/01463370701839057

Zoggel, G-v. (2011). Serious 'techno-intimacy': Perceiving Japanese dating simulation games as serious games. Retrieved from https://www.academia.edu/1120303/Se rious_techno-intimacy_Perceiving_ Japanese_dating_simulation_video_gam es_as_serious_games 


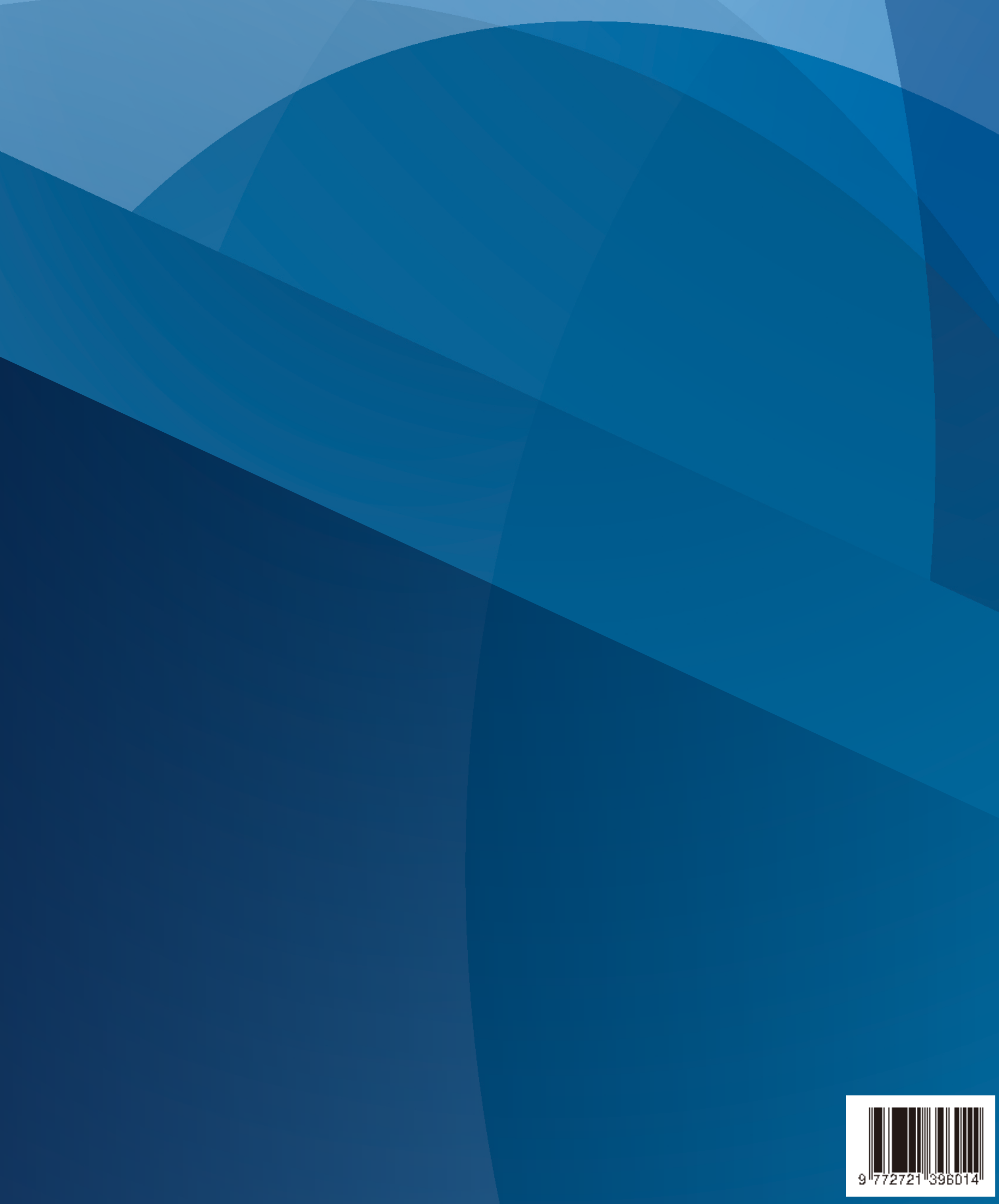

